JURNAL PUBLIPRENEUR: POLITEKNIK NEGERI MEDIA KREATIF

Vol. 8, No. 2, December 2020, hal. 56-74

Submitted: 5 December 2020

Revised: 15 December 2020

Accepted: 26 December 2020

\title{
STUDY OF DEFECT ON LLDPE PLUG FOR TELON OIL PRODUCTS USING A HAITIAN MOLDING INJECTION MACHINE 1600MA AT PT X
}

\author{
Mochammad Irfan Mahardika ${ }^{*}$, Handika Dany Rahmayanti², Abdul Majid ${ }^{3}$ \\ Jurusan Teknik Grafika, Politeknik Negeri Media Kreatif, Indonesia ${ }^{123}$
}

\begin{abstract}
The type of plastic packaging that is popular among the public is bottle packaging, plastic bottle packaging always has a bottle cap. Some people only know that the part of the bottle cap is only on the outer cap, even though the plastic bottle cap consists of two types, namely the outer cap (cap) and the inner cap (plug). The plastic material used to make the plug is Linear Low Density Polyethylene (LLDPE), a telon oil plug is produced using an injection molding machine, by inserting plastic pellets into the hopper and then heating it by the barrel, plastic pellets that have melted will be injected into the mold (print). In the process of making the telon oil plug, a defect was found. From the observation, it is known that several types of defects that occur during the LLDPE oil plug production process include black dot, flashing, and unmould / short shot. Defects that occur during the telon oil plug production process are caused by damage, contamination, and mismatches in the engine parameter settings. The purpose of this study is to determine the causes and solutions of defects that occur in LLDPE telon oil plugs with the HAITIAN 1600MA injection molding machine at PT X. Some solutions are made to reduce defects that occur in telon oil LLDPE plugs is to clean the material reservoir, repair or replace the mold, clean the hopper before loading the material, and set up the barrel parameter $180-230^{\circ} \mathrm{C}$, inject pressure 60 bar, holding pressure 30 bar, speed 17.8 seconds.
\end{abstract}

Keyword: Defect,Plug, Injection Moulding, Packaging

\section{KAJIAN DEFECT PADA PLUG LLDPE PRODUK MINYAK TELON DENGAN MESIN INJECTION MOULDING HAITIAN 1600MA DI PT X}

\begin{abstract}
ABSTRAK
Jenis kemasan plastik yang populer di kalangan masyarakat adalah kemasan botol, kemasan botol plastik selalu dilengkapi tutup botol. Sebagian masyarakat hanya mengetahui bagian tutup botol hanya pada bagian tutup luarnya saja padahal tutup kemasan botol plastik terdiri dari dua macam, yaitu tutup luar (cap) dan tutup dalam (plug). Material plastik yang digunakan untuk membuat plug yaitu Linear Low Density Polyethylene (LLDPE), plug minyak telon diproduksi dengan menggunakan mesin injection moulding, dengan cara memasukan biji plastik ke dalam hopper lalu dipanaskan oleh barrel, biji plastik yang sudah mencair akan diinjeksikan ke dalam mould (cetakan).
\end{abstract}


Dalam proses pembuatan plug minyak telon ditemukan adanya defect. Dari hasil pengamatan diketahui beberapa jenis defect yang terjadi pada saat proses produksi plug LLDPE minyak telon antara lain black dot, flashing, dan unmould/short shot. Defect yang terjadi pada saat proses produksi plug minyak telon disebabkan oleh kerusakan, kontaminasi, dan ketidaksesuaian dalam pengaturan parameter mesin. Tujuan dari penelitian ini untuk mengetahui penyebab, dan solusi dari defect yang terjadi pada plug LLDPE minyak telon dengan mesin injection moulding haitian 1600MA di PT X. Beberapa solusi yang dilakukan untuk mengurangi defect yang terjadi pada plug LLDPE minyak telon adalah dengan membersihkan tempat penampungan material, memperbaiki atau mengganti mould, membersihkan hopper sebelum memasukan material, dan melakukan set up parameter barrel $180-230^{\circ} \mathrm{C}$, inject pressure 60 bar, holding pressure 30 bar, speed 17,8 detik.

Kata kunci: Defect, Plug, Injection Moulding, Kemasan.

\section{PENDAHULUAN}

Jenis kemasan plastik yang populer di kalangan masyarakat adalah kemasan botol. Kemasan ini umumnya digunakan untuk mengemas berbagai jenis produk seperti minyak, minuman, produk kecantikan, serta obat-obatan. Kemasan botol plastik selalu dilengkapi tutup botol. Sebagian masyarakat hanya mengetahui bagian tutup botol hanya pada bagian tutup luarnya saja padahal tutup kemasan botol plastik terdiri dari dua macam, yaitu tutup luar (cap) dan tutup dalam (plug).

Fungsi plug botol pada umumnya adalah mencegah dan menyumbat isi produk agar tidak bocor dan tumpah saat digunakan serta untuk mencegah masuknya bakteri ke dalam botol. Material plastik yang digunakan untuk membuat plug yaitu Linear Low Density Polyethylene (LLDPE), karena memiliki sifat fisik dan mekanik yang bagus, tahan terhadap bahan kimia, sangat fleksibel, dapat berubah dibawah tekanan, dan sifat-sifat lain yang dibutuhkan oleh plug. Proses produksi yang paling sesuai untuk memproduksi plug secara masal yaitu proses Injection Moulding.

Dalam suatu proses produksi, sering ditemukan adanya produk yang tidak sesuai dengan standar kualitas yang telah ditetapkan oleh perusahaan. Produk tersebut bisa dikategorikan sebagai produk cacat atau defect. Defect pada produk yang timbul secara terus menerus dapat menimbulkan hambatan pada saat proses produksi berlangsung serta dapat mengakibatkan kerugian baik secara tenaga maupun finansial. Defect pada produk juga berdampak pada citra perusahaan di mata konsumen yang mempengaruhi kepercayaan konsumen terhadap perusahaan (Zulianto, 2015).

Dalam menjalankan produksinya perusahaan selalu berusaha agar produk yang dihasilkan mempunyai kualitas yang baik dan sesuai dengan kebutuhan konsumen. Namun pada kenyataannya jumlah produk cacat yang dihasilkan masih tinggi. Hal ini mengakibatkan tingginya kerugian yang dialami perusahaan, baik untuk memproses ulang produk tersebut maupun kerugian karena produk yang terbuang (Meriastuti, 2018).

Salah satu contohnya seperti yang terjadi di PT X. Salah satu produk yang diproduksi di PT $X$ adalah plug LLDPE minyak telon merek $\mathrm{Y}$ yang diproduksi menggunakan mesin Injection Moulding haitian 1600MA. Pada saat proses produksi berlangsung banyak terjadi kecacatan produk/defect. Hal ini mengakibatkan keterlambatan pengiriman pada konsumen dan mengakibatkan kerugian besar pada pihak perusahaan. Pada penelitian ini akan 


\section{JURNAL PUBLIPRENEUR: POLITEKNIK NEGERI MEDIA KREATIF Vol. 8, No. 2, December 2020, hal. 56-74}

Submitted: 5 December 2020

Revised: 15 December 2020

Accepted: 26 December 2020

diselidiki defect apa saja yang sering muncul pada proses produksi plug botol minyak telon merek Y di PT X, penyebab terjadinya defect serta bagaimana cara mengurangi terjadinya defect. Kajian ini penting dilakukan guna melakukan pencegahan untuk mengurangi timbulnya defect pada produk sehingga angka kerugian perusahaan dapat ditekan.

\section{METODE PENELITIAN}

Metode penelitian yang dilakukan adalah dengan melakukan observasi langsung ke PT $X$. Penulis melakukan pengumpulan data-data langsung dari pengamatan proses produksi plug botol minyak telon merek $Y$ dengan menggunakan mesin Injection Moulding haitian 1600MA maupun dengan cara wawancara serta diskusi dengan karyawan di PT X.

\section{HASIL DAN PEMBAHASAN}

Injection moulding adalah proses produksi pembuatan plastik dengan cara melelehkan material plastik yang kemudian diinjeksikan ke dalam sebuah cetakan yang disebut mould. Mesin injection moulding terdiri atas beberapa bagian seperti: hopper, barrer, nozzel, dan mould. Dalam proses produksi pembentukan plastik menggunakan mesin Injection Moulding tidak lepas dari cacat produk seperti sink mark, short shot, flashing, silver streak, warpage, black dot, bubble, string ataupun earline yang terjadi pada bagian-bagian tertentu suatu produk. Desain mould yang kurang optimal dan pengaruh parameter/setting mesin injection dapat mempengaruhi timbulnya beberapa jenis defect di atas sehingga mengakibatkan biaya produksi yang tinggi atau kurang efisien karena material banyak yang harus diproses ulang dan kuantitas produk menurun karena produk banyak yang rusak (Zulianto, 2015).

Pada saat proses produksi plug LLDPE minyak telon dengan mesin injection moulding haitian 1600MA di PT X terdapat beberapa defect yang terjadi diantaranya black dot, flashing, dan unmould/short shot. Black dot atau bintik hitam terjadi pada permukaan produk seperti ditungjukkan Gambar 1, defect ini termasuk kategori major defect karena mengurangi kualitas penampilan suatu produk.
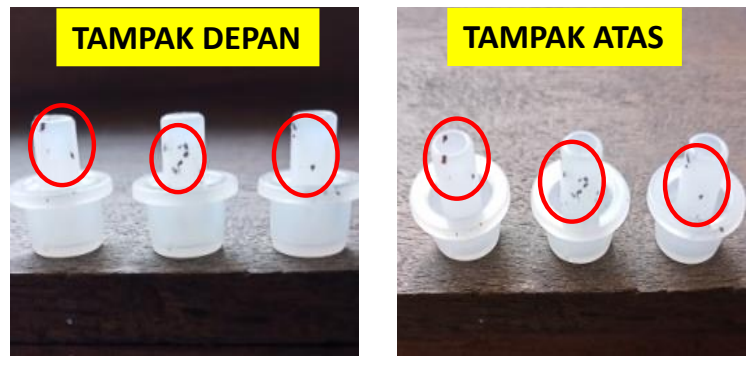

Gambar 1 Defect Black Dot pada Plug Botol Minyak Telon Merek Y

Selanjutnya defect Flashing seperti ditunjukkan Gambar 2. Flashing berarti terdapat material lebih yang ikut membeku di pinggir-pinggir produk, yakni suatu kondisi dimana hasil produk tercetak berlebihan dan memiliki bentuk yang tidak sesuai dengan cetakan. Flashing termasuk ke dalam kategori defect critical karena kecacatan yang dialami berpengaruh langsung terhadap fungsi dari plug sehingga plug tidak dapat digunakan. Namun flashing juga bisa termasuk jenis defect minor apabila plug masih bisa dikatakan dalam keadaan cukup baik tetapi harus dilakukan pembersihan dengan cara memotong material yang berlebih tersebut.
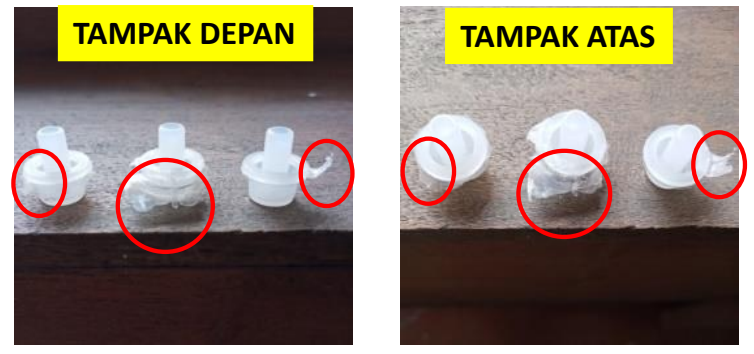

Gambar 2 Defect Flashing pada Plug Botol Minyak Telon Merek Y 
Terakhir Defect Unmould/short shot seperti ditunjukkan Gambar 3. Unmould/short shot adalah suatu kondisi dimana, plastik leleh yang akan diinjeksikan kedalam cavity tidak mencapai kapasitas yang ideal. Sehingga plastik yang diinjeksikan kedalam cavity mengeras terlebih dahulu sebelum memenuhi cavity. Unmould/short shot masuk kedalam kategori critical deffect karena produk secara dimensi tidak sesuai standar, dan daya guna dari produk pun menjadi berkurang.
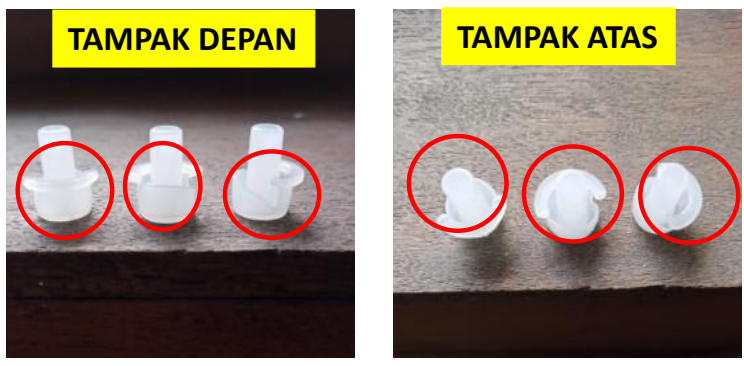

Gambar 3 Defect Unmold/Short Shot pada Plug Botol Minyak Telon Merek Y selama satu minggu pada data produksi tanggal 10 Februari sampai 14 Februari 2020 ditunjukkan pada Tabel 1. Penyebab terjadinya defect black dot karena adanya material yang terkontaminasi oleh kotoran atau material lain, mesin injection moulding haitian 1600MA memiliki hopper yang berfungsi untuk menampung material sebelum dilelehkan didalam barrel. Material yang kotor ketika proses penggilingan aval dan hopper yang kurang bersih akan mengakibatkan material yang tersimpan didalamnya dapat terkontaminasi. Kotoran yang terdapat pada hopper akan tercampur dengan material lalu ikut masuk ke dalam barrel dan akan tercetak oleh mould, sehingga menyebabkan plug yang dihasilkan memiliki noda bintik kehitaman.

Hasil pengamatan sejumlah defect

Tabel 1. Hasil Produksi dan Defect yang terjadi pada produksi Plug di PT X.

\begin{tabular}{|c|c|c|c|c|c|c|}
\hline \multirow[b]{2}{*}{ Tanggal } & \multirow{2}{*}{$\begin{array}{l}\text { Target } \\
\text { jumlah } \\
\text { produksi } \\
\text { perhari } \\
\text { (pcs) }\end{array}$} & \multicolumn{3}{|c|}{ Jenis defect } & \multirow{2}{*}{$\begin{array}{l}\text { Jumlah } \\
\text { produk } \\
\text { cacat } \\
\text { (pcs) }\end{array}$} & \multirow{2}{*}{$\begin{array}{l}\text { Jumlah } \\
\text { produksi } \\
\text { perhari } \\
\text { (pcs) }\end{array}$} \\
\hline & & $\begin{array}{l}\text { Black } \\
\text { dot }\end{array}$ & Flashing & $\begin{array}{l}\text { Un mould/ } \\
\text { short shot }\end{array}$ & & \\
\hline 10 Februari & 149.449 & 140 & 375 & 263 & 778 & 143222 \\
\hline 11 Februari & 149.449 & 126 & 412 & 245 & 783 & 143217 \\
\hline 12 Februari & 149.449 & 155 & 354 & 287 & 796 & 143204 \\
\hline 13 Februari & 149.449 & 128 & 326 & 254 & 708 & 143292 \\
\hline 14 Februari & 149.449 & 111 & 287 & 225 & 623 & 143377 \\
\hline
\end{tabular}

Pada proses produksi pembuatan plug menggunakan prinsip injection moulding material dalam bentuk biji plastik ditampung dalam sebuah hopper kemudian turun ke dalam barrel (karena gaya gravitasi) dimana biji plastik tersebut akan mencair oleh pemanas yang terdapat di dinding barrel dan perputaran screw barrel, biji plastik yang sudah mencair diinjeksikan oleh melalui 
nozzle ke dalam cetakan (cavity). Penyebab terjadinya defect flashing adalah adalah dikarenakan pelelehan biji plastik yang terlalu mencair, holding pressure yang kurang kuat, proses injeksi yang terlalu cepat, tekanan injeksi yang terlalu kuat, temperatur peleburan yang terlalu panas, temperatur mould yang terlalu tinggi. Sehingga material yang diinjeksikan mudah mengalir kesegala arah hal tersebut mengkibatkan produk yang tercetak melebihi kapasitas cetakan (cavity). Selain itu peran mould sangat penting, karena mould dapat mempengaruhi bentuk dari hasil produk yang dicetak. Mould yang tidak dapat tertutup rapat karena selama proses produksi berlangsung mould sering bertubrukan antara cavity dan core yang menyebabkan mould tersebut lama kelamaan akan terkikis dan menjadi renggang sehingga mould tidak dapat tertutup dengan rapat, ketika proses mould close biji plastik yang sudah dilelehkan didalam barrel akan diinjeksikan kedalam mould apabila mould tidak tertutup dengan rapat maka biji plastik akan mengalir keluar dari mould. Hal tersebut bisa menyebabkan flashing.

Penyebab terjadinya defect unmould/short shot adalah faktor human eror seperti kurangnya pemahaman cara mengoprasionalkan mesin injection moulding, sehingga saat diketahui jumlah defect produk yang begitu banyak tidak dengan segera ditangani. Adapun faktor lingkungan juga menjadi penyebab terjadinya defect unmould/shortshot misalnya suhu ruangan yang panas dikarenakan belum beroprasionalnya pemasangan AC sehingga membuat suhu pada mesin dapat saja berubah akibat suhu ruangan yang terlalu panas. Faktor lain yang mempengaruhi defect unmould/short shot adalah, kurang memperhatikan standar setting mesin injection moulding. Pada saat proses produksi pembuatan plug menggunakan prinsip injection moulding. Material dalam bentuk biji plastik ditampung dalam sebuah hopper kemudian turun ke dalam barrel (karena gaya gravitasi) dimana biji plastik tersebut akan mencair oleh pemanas yang terdapat di dinding barrel dan perputaran screw barrel. Biji plastik yang sudah mencair diinjeksikan oleh melalui nozzle ke dalam cetakan (cavity) dan didinginkan dengan menggunakan air. Produk yang sudah dingin dan mengeras dikeluarkan dari cetakan oleh pendorong (ejector). Pada saat proses pendinginan produk, secara bersamaan di dalam barrel terjadi proses pelelehan plastik sehingga begitu produk dikeluarkan dari cetakan dan cetakan menutup, material yang meleleh langsung dapat diinjeksi. Penyebab terjadinya defect unmould/short shot adalah dikarenakan pelelehan biji plastik yang tidak sempurna, proses injeksi yang lambat, tekanan injeksi yang lemah, mould yang kotor atau tersumbat, temperatur peleburan yang rendah, temperatur mould yang terlalu rendah. Sehingga mengkibatkan produk yang tercetak tidak semuanya mencapai kapasitas cetakan (cavity).

Penurunan jumlah produksi akibat terjadinya defect sangat merugikan perusahaan. Oleh karena itu diperlukan solusi untuk mengurangi defect yang terjadi. Adapun solusi yang dilakukan untuk mengurangi defect pada saat proses produksi plug LLDPE minyak telon dengan mesin injection moulding haitian 1600MA adalah 
sebagai berikut :

Solusi untuk mengurangi defect black dot sebelum memulai proses produksi harus memeriksa material untuk mencegah kemungkinan adanya kontaminasi dan dipastikan sekitar area produksi dan hopper pada mesin injection moulding haitian 1600MA dalam keadaan bersih dari kotoran atau material lain. Hopper dibersihkan dengan menggunakan vakum kemudian dibersihkan dengan menggunakan kain yang dibasahi sedikit alkohol, hal ini bertujuan supaya kotoran atau material sisa produksi sebelumnya yang berada didalam hopper dapat terangkat.

Solusi untuk mengurangi defect flashing pada proses pembuatan plug LLDPE minyak telon di PT X memiliki parameter injection moulding. Namun ketika proses produksi sedang berlangsung parameter mesin dapat berubah secara otomatis hal ini lah yang dapat menyebabkan terjadinya defect pada produk apabila tidak segera ditangani. Setelah melakukan beberapa produksi dan mengamati terjadinya flashing itu sendiri, maka penanganan yang dilakukan untuk mengurangi defect flashing adalah: Apabila disebabkan oleh parameter holding pressure yang melebihi 40 bar maka core akan terlalu menekan sehingga material yang diinjeksikan dapat keluar atau meluber melebihi cavity sehingga diperlukan penanganan oleh operator mesin dengan cara menurunkan settingan holding pressure 21-39 bar.

Apabila kecepatan injeksi dari barrel ke cavity terlalu cepat atau kurang dari 17 detik maka akan mengakibatkan material yang diinjeksikan melebihi cavity sebelum core menekan yang mengakibatkan material terlebih dahulu keluar dari cavity sehingga harus dilakukan

Tabel 2 Parameter proses injection moulding

\begin{tabular}{|l|l|l|l|l|}
\hline No & Parameter & Toleransi & $\begin{array}{l}\text { Sebelum } \\
\text { Diperbaiki }\end{array}$ & $\begin{array}{l}\text { Setelah } \\
\text { Perbaikan }\end{array}$ \\
\hline 1 & Temperatur Barrel Z1 & $10^{\circ} \mathrm{C}$ & $180^{\circ} \mathrm{C}$ & $180^{\circ} \mathrm{C}$ \\
\hline 2 & Temperatur Barrel Z2 & $10^{\circ} \mathrm{C}$ & $180^{\circ} \mathrm{C}$ & $180^{\circ} \mathrm{C}$ \\
\hline 3 & Temperatur Barrel Z3 & $10^{\circ} \mathrm{C}$ & $200^{\circ} \mathrm{C}$ & $200^{\circ} \mathrm{C}$ \\
\hline 4 & Temperatur Barrel Z4 & $10^{\circ} \mathrm{C}$ & $200^{\circ} \mathrm{C}$ & $200^{\circ} \mathrm{C}$ \\
\hline 5 & Temperatur Nozzel & $10^{\circ} \mathrm{C}$ & $220^{\circ} \mathrm{C}$ & $220^{\circ} \mathrm{C}$ \\
\hline 6 & Temperatur Manipol & $10^{\circ} \mathrm{C}$ & $230^{\circ} \mathrm{C}$ & $230^{\circ} \mathrm{C}$ \\
\hline 7 & Temperatur Gate / Jet Point & $10^{\circ} \mathrm{C}$ & $240^{\circ} \mathrm{C}$ & $240^{\circ} \mathrm{C}$ \\
\hline 8 & Inject Pressure & $10 \mathrm{bar} / 10 \%$ & 85 bar & 60 bar \\
\hline 9 & Holding Pressure & $10 \mathrm{bar} / 10 \%$ & 16 bar & 30 bar \\
\hline 10 & Speed & $10 \%$ & 15 detik & 17,8 detik \\
\hline 11 & Berat Produk & 0,1 gram & 0,7 gram & 0,7 gram \\
\hline
\end{tabular}


JURNAL PUBLIPRENEUR: POLITEKNIK NEGERI MEDIA KREATIF

Vol. 8, No. 2, December 2020, hal. 56-74

Submitted: 5 December 2020

Revised: 15 December 2020

Accepted: 26 December 2020

penanganan oleh operator dengan memperlambat kecepatan injeksi maksimal 10\% dari 18,5 detik. Apabila tekanan injeksi mterial dari nozzel ke cavity melebihi 70 bar maka material yang diinjeksikan akan tertekan keluar cavity yang akan mengakibatkan cavity over kapasitas dan tercetak tidak sesuai cetakan, penanganan yang dilakukan adalah dengan menurunkan tekanan injeksi sampai batas yang idealnya 60 bar dengan toleransi \pm 10 bar.

Apabila suhu pelelehan material dialam barrel melebihi $240^{\circ} \mathrm{C}$ akan mengakibatkan barrel mengeluarkan asap jika over heating dan material yang berada didalam barrel terlalu cair yang mengakibatkan ketika diinjeksikan ke cavity material tersebut bergerak ke segala arah dan cepat mengalir keluar cavity maka penanganan yang harus dilakukan adalah dengan cara menurunkan suhu pelelehan dibarrel yang idealnya adalah $180^{\circ}-230^{\circ} \mathrm{C}$.

Apabila semua parameter sudah sesuai dengan standar yang ditentukan tetapi masih terjadi defect flashing maka perlu dilakukan pengecekan mould karena mould yang digunakan sudah terkikis karena tubrukan mould sehingga mengakibatkan mould renggang dan tidak dapat tertutup rapat maka diperlukan perbaikan mould di mould shop.

Jadi secara garis besar solusi yang dilakukan untuk mengurangi defect flashing adalah dengan menurunkan holding pressure, menurunkan kecepatan injeksi material, menurunkan tekanan injeksi, menurunkan suhu material sesuai dengan batasannya. Dan dengan melakukan perawatan secara berkala terhadap mould yang digunakan untuk memproduksi plug atau mengganti mould yang usianya sudah tua, karena mould yang sudah terlalu tua akan mengakibatkan mould tidak dapat tertutup rapat, karena mould sering mengalami tubrukan maka akan terkikis sehingga pada saat proses mould close akan terjadi kerenggangan yang mengakibatkan terjadinya flashing.
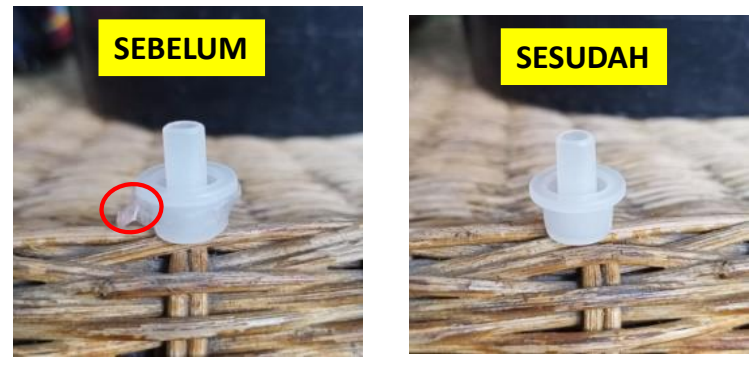

Gambar 4. Defect Flashing sebelum dan sesudah dilakukan perbaikan

Selanjutnya, solusi untuk mengurangi defect unmould/short shot pada proses pembuatan plug LLDPE minyak telon di PT $X$ memiliki parameter injection moulding. Namun ketika proses produksi sedang berlangsung parameter mesin dapat berubah secara otomatis hal ini lah yang dapat menyebabkan terjadinya defect pada produk apabila tidak segera ditangani. Setelah melakukan beberapa produksi dan mengamati terjadinya defect unmould/short shot itu sendiri, maka penanganan yang dilakukan untuk mengurangi defect unmould/short shot adalah: Apabila nozzel tersumbat oleh sisa-sisa material yang membeku maka akan mengakibatkan terhambatnya proses injeksi material dari barrel menuju cavity sehingga material yang diinjeksikan kedalam cavity tidak sempurna yang menyebabkan produk yang tercetak tidak sesuai cetakan, penanganaan yang 
harus dilakukan adalah dengan memeriksa nozzel secara berkalaa setiap 1-2 jam sekali apabila terjadi gumpalan maka harus segera dibersihkan.

Apabila kecepatan injeksi dari barrel ke cavity terlalu lambat atau melebihi dari 20 detik maka akan mengakibatkan material yang diinjeksikan tidak seluruhnya memenuhi cavity pada saat proses pendinginan berlangsung yang mengakibatkan material terlebih dahulu membeku di cavity sebelum material sepenuhnya masuk ke cavity maka tindakan penanganan yang harus dilakukan adalah dengan mempercepat kecepatan injeksi maksimal 10\% dari 18,5 detik.

Apabila tekanan injeksi material dari nozzel ke cavity kurang dari 50 bar maka material yang diinjeksikan tidak akan memenuhi cavity yang akan mengakibatkan ketika proses pendinginan material yang membeku tidak full cavity dan tercetak tidak sempurna, maka penanganan yang harus dilakukan adalah dengan menaikan tekanan injeksi sampai batas yang idealnya 60 bar dengan toleransi \pm 10 bar. Apabila suhu pelelehan material dialam barrel kurang dari $160^{\circ} \mathrm{C}$ akan mengakibatkan screw barrel patah karena material yang berada didalam barrel tidak meleleh seluruhnya sehingga screw yang berputar terganggu oleh material yang masih belum meleleh yang mengakibatkan ketika material diinjeksikan kedalam cavity akan melambat dan pada saat proses pendinginan material belum sepenuhnya memenuhi cavity maka

Tabel 2 Parameter proses injection moulding

\begin{tabular}{|l|l|l|l|l|}
\hline No & Parameter & Toleransi & $\begin{array}{l}\text { Sebelum } \\
\text { Diperbaiki }\end{array}$ & $\begin{array}{l}\text { Setelah } \\
\text { Perbaikan }\end{array}$ \\
\hline 1 & Temperatur Barrel Z1 & $10^{\circ} \mathrm{C}$ & $180^{\circ} \mathrm{C}$ & $180^{\circ} \mathrm{C}$ \\
\hline 2 & Temperatur Barrel Z2 & $10^{\circ} \mathrm{C}$ & $180^{\circ} \mathrm{C}$ & $180^{\circ} \mathrm{C}$ \\
\hline 3 & Temperatur Barrel Z3 & $10^{\circ} \mathrm{C}$ & $200^{\circ} \mathrm{C}$ & $200^{\circ} \mathrm{C}$ \\
\hline 4 & Temperatur Barrel Z4 & $10^{\circ} \mathrm{C}$ & $200^{\circ} \mathrm{C}$ & $200^{\circ} \mathrm{C}$ \\
\hline 5 & Temperatur Nozzel & $10^{\circ} \mathrm{C}$ & $220^{\circ} \mathrm{C}$ & $220^{\circ} \mathrm{C}$ \\
\hline 6 & Temperatur Manipol & $10^{\circ} \mathrm{C}$ & $230^{\circ} \mathrm{C}$ & $230^{\circ} \mathrm{C}$ \\
\hline 7 & Temperatur Gate / Jet Point & $10^{\circ} \mathrm{C}$ & $240^{\circ} \mathrm{C}$ & $240^{\circ} \mathrm{C}$ \\
\hline 8 & Inject Pressure & $10 \mathrm{bar} / 10 \%$ & $85 \mathrm{bar}$ & $60 \mathrm{bar}$ \\
\hline 9 & Holding Pressure & $10 \mathrm{bar} / 10 \%$ & 16 bar & 30 bar \\
\hline 10 & Speed & $10 \%$ & 15 detik & 17,8 detik \\
\hline 11 & Berat Produk & 0,1 gram & 0,7 gram & 0,7 gram \\
\hline
\end{tabular}

penanganan yang harus dilakukan adalah dengan cara menaikan suhu 


\section{JURNAL PUBLIPRENEUR: POLITEKNIK NEGERI MEDIA KREATIF Vol. 8, No. 2, December 2020, hal. 56-74}

Submitted: 5 December 2020

Revised: 15 December 2020

Accepted: 26 December 2020

pelelehan barrel yang idealnya adalah $180^{\circ}-230^{\circ} \mathrm{C}$. Apabila semua parameter sudah sesuai dengan standar yang ditentukan tetapi masih terjadi defect unmould/short shot maka perlu dilakukan pengecekan mould karena mould yang digunakan bisa jadi tersumbat oleh material yang tidak meleleh sehingga harus dilakukan dengan cara membersihkan mould dari kotoran-kotoran yang mungkin mengganggu aliran material ke dalam cavity dengan pelumas demorrist green.

Jadi secara garis besar solusi yang dilakukan untuk mengurangi defect unmould/short shot adalah dengan memastikan supply material harus selalu berkelanjutan jangan sampai ada jeda, meningkatkan kecepatan injeksi material, meningkatkan tekanan injeksi, meningkatkan suhu material sesuai dengan batasannya, membersihkan mould dari kotoran-kotoran yang mungkin mengganggu aliran material ke dalam cavity.
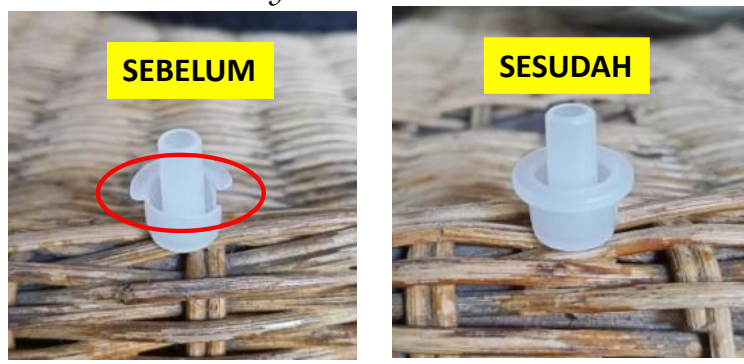

Gambar 5. Defect Unmold sebelum dan sesudah dilakukan perbaikan

\section{KESIMPULAN}

Defect yang terjadi pada plug LLDPE minyak telon dengan mesin injection moulding haitian 1600MA adalah blackdot, flashing, dan unmould/shortshot. Penyebab defect blackdot karena hopper kurang bersih saat pengisian material, ketika pencampuran dengan material aval.
Aval yang digunakan sudah terkontaminasi. Penyebab terjadinya defect flashing karena temperatur peleburan terlalu tinggi, mould tidak tertutup rapat, holding presure yang kurang kuat, proses injeksi yang terlalu cepat, tekanan injeksi terlalu kuat. Penyebab terjadinya defect unmould/short shot karena pelelehan biji plastik yang tidak sempurna, tekanan injeksi kurang kuat, kondisi mould yang kotor atau tersumbat, temperatur peleburan rendah, tekanan injeksi kurang kuat, proses injeksi yang lambat. Solusi yang dilakukan untuk mengurangi defect yang terjadi pada plug LLDPE minyak telon dengan mesin injection moulding haitian 1600MA adalah Sebelum memulai proses produksi harus membersihkan hopper dan memeriksa material untuk mencegah kemungkinan adanya kontaminasi dan pastikan sekitar area produksi dalam keadaan bersih. Untuk mengurangi defect flashing dengan melakukan setting parameter yang ada pada mesin injection moulding dan melakukan perawatan mould apabila mould yang digunakan sudah tua dan terkikis maka solusi yang tepat adalah dengan mengganti mould. Untuk mengurangi defect unmould/short shot dengan melakukan setting parameter yang ada pada mesin injection moulding dan membersihkan mould dari kotoran atau material sisa yang dapat mengganggu aliran material ke dalam cavity.

\section{DAFTAR PUSTAKA}

Julianti, Sri. 2014. The Art of Packaging. Jakarta: PT Gramedia Pustaka Utama

Maflahah, Iffan. 2016. Teknologi 


\section{Pengemasan}

M.S, Didik HM. 2017. Diktat

Perkuliahan Program Studi

Teknik Kemasan, Jurusan Teknik

Grafika, Mata Kuliah Ilmu

Pengetahuan Plastik

M.S, Didik HM. 2017. Diktat

Perkuliahan Program Studi

Teknik Kemasan, Jurusan Teknik

Grafika, Mata Kuliah Pengantar

Ilmu Kemasan

Soroka, Walter. Fundamental of

Packaging Technology. United

Kingdom (UK). The Institute of Packaging

Zulianto, Dwi. 2015. Analisa Pengaruh Variasi Suhu Plastik Terhadap Cacat Warpage pada Produk Injection Moulding

Sucipta, Nyoman. 2017. Pengemasan Pangan, Kajian Pengemasan yang Aman, Nyaman, dan Efisien

Ginting, Meriastuti. 2018. Minimalisasi Produk Cacat Proses Injection Moulding

Ikpom. 2010. Plastik Sebagai Kemasan Pangan

Id.wikipedia.org. Tutup botol Wikipedia bahasa Indonesia, ensiklopedia bebas. Yang diakses pada tanggal 12 juni 2020 pukul $12: 53$ 